\title{
SOCIEDAD DE HECHO: ¿EMPRENDER O FRACASAR?
}

\section{DE FACTO CORPORATION: TO UNDERTAKE OR TO FAIL?}

\section{SOCIEDADE DE FATO: EMPREENDER OU FRACASSAR?}

\author{
CIRO CAMETO ACOSTA NELL ${ }^{1}$, MARTÍN CÁNEPA SALABERRY ${ }^{2} Y$ \\ ALEC JOHN LEAMAN DOMÍNGUEZ ${ }^{3}$
}

\author{
RECIBIDO: $7 / 11 / 2020$ \\ ACEPTADO: $13 / 11 / 2020$
}

\begin{abstract}
RESUMEN: La sociedad comercial de hecho es uno de los tipos sociales más utilizado por los emprendedores a la hora de realizar negocios. En el siguiente trabajo el lector se encontrará con un análisis exhaustivo del régimen legal aplicable a este tipo social y de las dificultades que presenta su constitución, funcionamiento y disolución, tanto desde una perspectiva doctrinaria como jurisprudencial, lo que permitirá determinar si emprender bajo esta forma garantiza el éxito o el fracaso del negocio.
\end{abstract}

PALABRAS CLAVE: Sociedad de Hecho; Sociedad comercial de hecho; Sociedades Comerciales; Constitución de sociedad de hecho; Funcionamiento de sociedad de hecho; Disolución de sociedad de hecho.

ABSTRACT: De facto company is one of the types most adopted by entrepreneurs when doing business. Through the following pages, the reader will access to a exhaustive analysis of the legal regulation applicable to this company type and the difficulties that its constitution, operation and dissolution arise, from the perspective of doctrine and judgments, which will allow to determine if undertaking under this company type guarantees the success or failure of the business.

KEY WORDS: De facto company; De facto commercial company, Companies, De facto company constitution, De facto company operation, De facto company dissolution.

RESUMO: A sociedade comercial de fato é um dos tipos mais utilizados pelos empreendedores na hora de realizar negócios. No presente trabalho, o leitor encontrará uma análise exaustiva do regime jurídico aplicável a esse tipo de sociedade e das dificuldades

1 Procurador por Universidad de Montevideo. Estudiante de abogacía, Universidad de Montevideo. ORCID ID: https://orcid.org/0000-0001-6784-795X. ccameto@correo.um.edu.uy

2 Procurador por Universidad de Montevideo. Estudiante de abogacía y notariado, Universidad de Montevideo. ORCID ID: https:/ / orcid.org/0000-0002-3930-2562. mcanepa@correo.um.edu.uy

3 Procurador por Universidad de Montevideo. Estudiante de Abogacía, Universidad de Montevideo. ORCID ID: https://orcid.org/0000-0002-8356-245X. aleaman@correo.um.edu.uy 
que apresenta a sua constituição, funcionamento e dissolução, tanto de uma perspectiva doutrinária como jurisprudencial, o que permitirá determinar se empreender sob esta forma garante o sucesso ou o fracasso do negócio.

PALAVRAS - CHAVE: Sociedade de Fato, Sociedade Comercial de Fato, Sociedades comerciais; Constituição de sociedade de Fato; Funcionamento da sociedade de fato; Dissolução da sociedade de fato.

\section{Regulación}

Dentro del esquema societario uruguayo nos encontramos con un abanico de tipos sociales o vehículos jurídicos a disposición del interesado para decidir emprender.

En la Ley No16.060 (en adelante, “LSC") podemos encontrar sociedades personales, así como sociedades de capital. El criterio de distinción entre ambas radica en la posibilidad de transferir libremente la participación social ${ }^{4}$. Entre las primeras encontramos la sociedad de responsabilidad limitada y la sociedad colectiva, mientras que en el segundo grupo podemos hallar las sociedades anónimas.

Otro tipo social muy difundido es la sociedad comercial de hecho, a la que la LSC también dedica artículos (36 a 43) para su regulación. A continuación analizaremos qué es una sociedad de hecho, sus ventajas y desventajas.

\section{Definición de la sociedad de hecho}

En la LSC la regulación de la sociedad de hecho se encuentra asimilada a la regulación correspondiente a la sociedad irregular. No contiene una definición de qué es una sociedad de hecho, sin perjuicio de que contiene algunos elementos que permiten su caracterización.

Para definir a la sociedad de hecho podemos dividir su denominación en dos partes. En primer lugar, se trata de un sociedad, y como tal debe cumplir con todos los requisitos previstos en el art. 1 de la LSC.

Para que exista sociedad, y también sociedad de hecho, es necesario que dos o más personas, físicas o jurídicas se obliguen a realizar aportes para aplicarlos al ejercicio de una actividad comercial organizada, con el fin de participar en las ganancias y soportar las pérdidas que ella produzca (art. 1 de la LSC).

Este es el primer elemento a tener en cuenta por cuanto será el primer aspecto que debemos analizar para dilucidar si estamos frente a una sociedad de hecho, esto es, si encontramos los clásicos elementos que hacen a la sociedad. Si no hallamos los elementos de la sociedad, debemos buscar otra institución jurídica que permite regular la situación.

En este sentido se ha pronunciado el TAC $2^{\circ}$ en sentencia $n^{\circ} 172 / 016^{5}$. En el caso se trataba de la explotación de un establecimiento comercial heredado del Sr. Buckstein, "Suc. Enrique Buckstein", de la que se habían hecho cargo sus dos hijos varones. La explotación se realizaba en un inmueble, que pertenecía también a la hermana de estos,

4 Lapique, Luis, Sociedades por acciones simplificadas, $1^{\text {a }}$ edición, Montevideo, FCU, 2020, pág. 31.

5 Sentencia 172/016 del TAC 2 ${ }^{\circ}$, de 30/11/2016, França (R), Sosa Aguirre y Pérez Brigniani. 
Silvina Buckstein, que figuraba en los organismos fiscales y ante el Ministerio de Trabajo y Seguridad Social (MTSS). Los hermanos iniciaron en contra de ella una acción declarativa de la calidad de socio de la sociedad de hecho. El Tribunal entendió que, en primer lugar, debía determinar si existía sociedad: "Lo que la parte actora debía probar para poder considerar a Silvina Buckstein como socia era si realizó algunos de los actos descriptos en la norma mencionada (Art. 1 de la LSC). Esto es si se obligó junto con otras personas a realizar aportes para aplicarlos a los fines de realizar una actividad comercial y por tanto no debe confundirse el hecho de ser cotitular o condómino del establecimiento comercial heredado con ser socio de la sociedad que lo explota"6.

El mismo Tribunal en sentencia $n^{\circ}$ 0005-000131/20157, en ocasión de resolver la existencia de una sociedad de hecho comercial entre ex concubinos, calificó que "debe acreditarse que se han realizado aportes, por ser este un requisito esencial de la sociedad, debiendo quedar acreditado que el trabajo personal o los bienes se han allegado al giro económico, destinado a producir utilidades, a título de aporte societario y no a otro título. Tiene que demostrase que ambos han hecho aportes, en bienes o trabajos con el fin de realizar una gestión económica común para obtener y repartir utilidades. Cabe señalar que para el caso de aportes en trabajo la naturale$z a$, y el modo y continuidad con que se las prestó deben ser las que corresponde a un socio según el orden normal de los sucesos; si es así se podrá extraer la conclusión de que la sociedad existió".

En sentencia $\mathrm{n}^{\circ} 167 / 018$ el TAC $2^{\circ}$ manifestó que "para que haya sociedad comercial deben verificarse los requerimientos establecidos en el art. 1 de la Ley No. 16.060, exigencias que se derivan del Derecho francés, también recogidas por el argentino. Ellas son: 1) la puesta en común de las contribuciones, sujetas a la evaluación financiera, realizada por cada uno de los contratistas; 2) la participación de todos los contribuyentes en los beneficios, y su contribución correlativa a las pérdidas que pueden resultar de la empresa y 3) La "affectio societatis", o sea, la colaboración voluntaria en vista a un objetivo común consistente en la realización de un beneficio para repartir"

No toda sociedad que cumpla con los requisitos del art. 1 de la LSC será una sociedad de hecho. Por el contrario, lo típico de este tipo social lo encontramos en la segunda parte de su denominación, en cuanto es "de hecho".

Siguiendo a Miller, la sociedad de hecho se caracteriza por no estar instrumentada por escrito, y por tanto, tampoco puede cumplir con los requisitos formales para su tipo social, sin perjuicio de que se convino entre los socios ${ }^{9}$.

En este sentido en sentencia $n^{\circ} 23 / 015$ del Juzgado Letrado de Primera Instancia en lo Civil de $17^{\circ}$ se definió a la sociedad de hecho "como las sociedades cuya constitución no se ha documentado por escrito ni han cumplido con los requisitos legales externos exigidos para la constitución de las sociedades comerciales" ${ }^{\prime 10}$.

Además de la falta de instrumentación, la LSC establece cuáles son sus efectos, formas de regularización y el régimen de responsabilidad, según comentaremos.

Entonces, del análisis de los dos elementos antes mencionados podemos definir a la sociedad de hecho como aquella persona jurídica formada mediante un contrato social

\footnotetext{
6 Sentencia $172 / 016$ del TAC $2^{\circ}$.

7 Sentencia 131/2015, 7/10/2015, Pérez Brignani (R), Sosa Aguirre y França Nebot.

8 Sentencia 167/018 de TAC 2 ${ }^{\circ}, 10 / 10 / 2018$, Pérez Brignani (R), Sosa Aguirre y França.

9 Miller, Alejandro. "Actividad empresarial mercantil y Sociedad de Hecho" en LJU Tomo 149, D-67.

10 Sentencia 23/015 de JL Civil 17º 22/6/2015, Hernández.
} 
que no se encuentre documentado en escritura pública o documento privado, por intermedio del cual las partes se obligan a realizar aportes para el desarrollo de una actividad comercial organizada, participando en las ganancias y soportando las pérdidas.

En este sentido se han manifestado otros autores. PIANTONI define a la sociedad de hecho como aquella cuyo contrato social tiene los mismos caracteres de todo contrato de sociedad, pero puede celebrarse verbalmente. ${ }^{11}$ No compartimos la definición dada por este autor, dado que cuando referimos a la sociedad de hecho, el contrato social debe estar necesariamente acordado en forma verbal.

Otra definición ha sido dada por Carvalho de Mendoça, quien entiende que la sociedad de hecho es aquella que, estando viciada de nulidad, continúa actuando como si fuera una sociedad válida ${ }^{12}$. No compartimos que la sociedad de hecho sea nula, sino que como explicaremos, se trata de una situación de precariedad jurídica, donde la regulación jurídica en lo que refiere a la relación de la sociedad con terceros es muy gravosa para sus socios, quienes probablemente, sin conocimiento alguno, hayan adoptado este tipo social.

\section{Análisis de la definición dada}

\section{La personería jurídica de la sociedad de hecho}

Entrando a un análisis de esta definición dada en primer lugar hay que prestar atención al vocablo persona jurídica. La sociedad comercial de hecho en Uruguay es persona jurídica, a diferencia de lo que ocurre en otras jurisdicciones.

Si bien la ley no establece a texto expreso la existencia de personalidad jurídica, esta puede ser fácilmente inferida. En primer lugar, el artículo 2 de la LSC establece a texto expreso un principio general que podría ser aplicable a todas las sociedades comerciales: "La sociedad comercial será sujeto de derecho desde la celebración del contrato social y con el alcance fijado en esta ley."

Este artículo no condiciona la personería jurídica de la sociedad comercial a la celebración de un contrato social por escrito, sino a la mera existencia de un contrato social, por lo que entendemos que la sociedad de hecho tiene personería jurídica al amparo de la LSC.

Asimismo, entendemos que en aquellos casos en los que el legislador no quiso otorgar la personalidad jurídica lo dispuso a texto expreso, como lo hizo en el artículo 483 de la LSC en materia de sociedades accidentales.

Con más precisión la propia regulación específica de sociedades de hecho nos da a entender la existencia de la personería jurídica. Así lo prevé el inciso $2^{\circ}$ del artículo 37 de la LSC que establece que la sociedad podrá ejercer contra terceros los derechos emergentes de la actividad social realizada. En tanto puede ejercer derechos, ello implica que existe jurídicamente como una entidad separable de sus socios.

No hay discordancias en la doctrina nacional relativas a la existencia de la personería jurídica en la sociedad de hecho comercial.

11 PIANTONI, Mario, Sociedades de Hecho e Irregularmente Constituidas Civiles y Comerciales, Editora Córdoba, 1981, p.33.

12 MEZZERA, Rodolfo, Curso de Derecho Comercial Tomo II, ACALI, 1983, p.86. 
Como consecuencia de la existencia de personería jurídica de la sociedad de hecho, podemos afirmar que:

a) tienen un nombre o razón social o ambas denominaciones lo que permite su distinción de las otras sociedades mercantiles. Respecto al nombre puede combinarse los nombres de los socios con el aditivo "sociedad de hecho" o funcionar con una denominación de fantasía con el mismo aditivo.

b) tiene un domicilio y sede como cualquier otra sociedad comercial, distinto al de sus socios. Sin perjuicio de ello, dado que la LSC tiene como objeto proteger al tercero frente a la sociedad de hecho, entendemos que puede ser emplazada válidamente en cualquier lugar donde haya operado, así como en el domicilio de sus socios, dado que cuando se emplaza a estos, se está emplazando a la sociedad por la representación legal que corresponde a estos (art. 39 de la LSC).

Entendemos que no se puede actuar con severidad a la hora de analizar cuál es el domicilio societario de este tipo de sociedades dado que difícilmente los socios, al constituir esta sociedad, hayan determinado un domicilio en donde se llevaría su administración.

Esta situación se agrava cuando la sociedad de hecho no funciona en un determinado establecimiento, y existe cierto anonimato de sus socios, por ejemplo, cuando interviene a través de redes sociales. Difícilmente los terceros puedan conocer quiénes se encuentran detrás de la sociedad. Una alternativa sería lograr el acceso a los registros que llevan los organismos fiscales (DGI, BPS), ante los cuales se registran las sociedades de hecho, y asumir que quienes se encuentran inscriptos son sus socios. En caso de que no exista registro alguno ante organismos fiscales, la sociedad de hecho se encuentra en situación de ventaja dado que el éxito de determinar ubicación y socios de la sociedad de hecho dependerá de la actividad probatoria realizada judicialmente, por ejemplo, mediante peritos informáticos, lo que puede implicar costos injustificados para los interés económicos en juego.

c) tiene "capacidad" para obligarse. La intervención de las sociedades de hecho es algo perceptible en el comercio, de hecho, la posibilidad de inscribirse en la Dirección General Impositiva y en el Banco de Previsión Social son claros indicios de que su rol no es irrelevante, al menos para el Estado.

También es posible encontrar publicados en la web diversos instructivos de instituciones de intermediación financiera con formularios para que sociedades de hecho puedan abrir cuentas corrientes en dichas entidades.

Distintas sentencias reconocen que las sociedades de hecho pueden contratar, y lo puede hacer un socio en representación de la sociedad, tal como comentaremos al mencionar la relación con terceros.

Así, en sentencia $\mathrm{n}^{\circ}$ SEF-0009-000005/2015 del T.A.C. $4^{\circ}$ se sostuvo: "Debe de verse, que ha sido admitido por la apelante en la contestación que COMECA "contrató con la sociedad de hecho integrada por Wilmar García Morales y Jorge Marenales Zeballos y que dicha sociedad se hizo cargo de la conducción de los móviles de traslados especializados y comunes, así como el mantenimiento de la flota de automotores utilizada por el Grupo Médico que presta la asistencia de emergencia (SEMIC) de COMECA"13.

13 Sentencia SEF-0009-000005/2015de TAC 4º , 2/2/2015, Maggi (R), Turell y Gatti. 
También lo ha reconocido el T.A.C. $6^{\circ}$ en sentencia $n^{\circ}$ SEF-0006-000066/2015 en donde la URSEC promovió demanda de recisión de contrato que había celebrado con “Breijo Sociedad de Hecho"14.

d) tiene la calidad de comerciante, y como tal, todos los derechos y obligaciones derivados de tal estado; por ejemplo, la lleva de libros de comercio;

e) tiene un patrimonio propio constituido por los aportes realizados por los socios y los bienes adquiridos por la sociedad durante la vida de esta; en el caso de las aportaciones supone una trasmisión de derechos del socio que aporta a la sociedad.

La sociedad de hecho puede ser titular de distintos derechos y bienes, muebles e inmuebles, salvo prohibición expresa de la ley. Cabe señalar que no existe limitación en cuanto al bien objeto de aporte, a diferencia de lo que ocurre en otras jurisdicciones, como en Argentina donde se prohíbe aportar bienes registrables. El proyecto de ley original uruguayo adoptó la misma solución que la ley argentina, pero se optó por eliminar esta limitación.

A modo de ejemplo, un establecimiento comercial puede ingresar dentro del patrimonio de la sociedad de hecho. Así se vio en la Consulta realizada ante la Comisión de Derecho Comercial de la Asociación de Escribanos del Uruguay publicada en la Revista de la Asociación de Escribanos, Tomo 104, en el que, una sociedad de hecho integrada por cónyuges era propietaria de un establecimiento comercial del ramo de farmacias. La sociedad se dio de baja en DGI y BPS, e intentaron inscribir el establecimiento comercial a nombre de uno de los integrantes 102/2011102/2011 de la sociedad ante el MSP. Ello fue observado en tanto correspondía a la sociedad enajenar el establecimiento comercial a su integrante, o disolver y liquidar la sociedad, adjudicando el bien a dicho socio. Esto demuestra que la sociedad de hecho tiene un patrimonio, distinguible del patrimonio de sus socios, sin perjuicio de la responsabilidad que corresponde a estos.

La autonomía patrimonial de la sociedad de hecho determina que los socios no sean copropietarios de los bienes sociales. Esto implica que no sea necesario contar con la conformidad de los cónyuges de cualquiera de los socios para enajenar bienes inmuebles.

Asimismo existe incomunicabilidad de las deudas de los socios a la sociedad, y es posible que la sociedad concurse independientemente de sus socios.

f) La sociedad de hecho tiene legitimación para comparecer en juicio.

En reiteradas instancias, la Jurisprudencia ha reconocido la aptitud de la sociedad de hecho comercial para comparecer en juicio, estando legitimado tanto activa como pasivamente. Ello no deja de ser una expresión de lo previsto en el artículo 37 de la LSC: "Sin embargo, la sociedad podrá ejercer contra terceros los derechos emergentes de la actividad social realizada."

En Sentencia n²6/010 del Juzgado de Paz Departamental de la Capital de $31^{\circ}$ Turno se cuestionó la legitimación activa de la sociedad de hecho para comparecer en un proceso de rescisión de contrato de arrendamiento de obra seguido contra un taller mecánico, que tenía en reparación un vehículo automotor propiedad de una de las socias de la sociedad hecho. La demandada impugnó la legitimación activa de la sociedad de hecho para comparecer en el proceso, en tanto quien resultaba legitimada era la propietaria

14 Sentencia SEF-0006-000066/2015 de TAC 6º 13/8/2015, Álvez de Simas (R), Klett y Martínez Rosso. 
del vehículo, teniendo presente que, a la fecha de la celebración del contrato, la sociedad de hecho no existía. Asimismo, se habían emitido facturas a nombre de la sociedad de hecho. Esto resultó insuficiente a juicio del tribunal para que resulte legitimada. Asimismo, se logró probar que la constitución de la sociedad fue posterior a la celebración del contrato de arrendamiento: $Y$ si se solicitó que se emitieran facturas de reparación y compra de repuestos a nombre de la sociedad fue únicamente y como bien supone la demandada, a los únicos efectos de poder descontar el IVA a través de la misma, pero que ello por sí no puede nunca habilitarla a ser demandante por los hechos acaecidos con el vehículo de propiedad de la Sra. Montiel ${ }^{15}$.

La sentencia antedicha fue confirmada por la sentencia ${ }^{\circ} 98 / 010$ del Juzgado Letrado en lo Civil de $5^{\circ}$ Turno que afirmó: "Se concuerda con el sentenciante de la etapa anterior entonces, en que si al momento de la rotura de la camioneta no existía la sociedad de hecho $M-G$, mal podría esta sociedad comparecer como codemandante. Las facturas emitidas, a nombre de V.M., o de " $A V$ " (un simple nombre de fantasía), o sin nombre de consumidor, nada agregan ni quitan cuando los hechos datan de enero de 2007 y a esa época no existía la sociedad M-G"16.

También comparecieron los representantes de la sociedad de hecho en sentencia no59/011 del Juzgado Letrado de $1^{\text {a }}$ en lo Civil de $11^{\circ}$ Turno, legitimación activa que no fue cuestionada ${ }^{17}$.

Asimismo, se ha reconocido la legitimación pasiva de la sociedad de hecho en sentencia $n^{\circ} 77 / 013$ de Juzgado Letrado de $1^{a}$ Instancia en lo Civil de $3^{\circ}$ Turno donde se demandó a dos arquitectos por vicios de la construcción encomendada, ambos directores y únicos accionistas de una sociedad anónima encargada de la construcción. Los arquitectos demandados opusieron excepción de falta de legitimación pasiva. No obstante, la parte actora se opuso a tal excepcionamiento aduciendo que ambos actuaban ante terceros, haciendo conocer el estudio de arquitectos que tenían en conjunto, incluso lo publicitaban a través de su página web. El tribunal entendió que ambos arquitectos podían ser demandados en tanto habían conformado una sociedad de hecho, y su legitimación pasiva resultaba del art. 39 de la LSC: adelantando posición se irá a desestimar la excepción opuesta por los arquitectos pues los mismos al haber conformado un estudio y presentarse a terceros como tal, como un estudio de arquitectos, como una unidad, debe entenderse que tienen una sociedad de hecho, salvo prueba en contrario y ello no ocurrió, por el contrario lo han reconocido. Es decir, no se contrató con el Arq. Neri o con el Arq. Collet a título particular, sino que se contrató con el Estudio de Arquitectos COLLET-NERI, y luego los profesionales se encargan de distribuir tareas internamente que al cliente no le debe interesar, más allá de la confianza que tenga depositada en alguno en particular o que llegue al estudio a través del conocimiento personal con alguno de los profesionales como ocurrió en el caso ${ }^{18}$.

\section{Constitución de la sociedad de hecho}

Adherimos a lo expuesto por BIASCO ${ }^{19}$ en cuanto a que el ámbito de la sociedad de hecho está en la pequeña y mediana empresa, en la empresa familiar y en el emprende-

\footnotetext{
15 Sentencia 26/010 de J. Paz Departamental de la Capital de $31^{\circ}$ Turno, 24/8/2010, Sarkisian.

16 Sentencia 98/010 de JL Civil 5 , 29/11/2010, Ettlin.

17 Sentencia 59/011 de JL CIVIL 11' $26 / 9 / 2011$, Opperti.

18 Sentencia 77/013 de JL Civil 3 ${ }^{\circ}, 30 / 10 / 2013$, Kelland.

19 BIASCO, Emilio, Sociedades de hecho y regulares en Revista AEU No69, 1983, p.518.
} 
durismo. Se trata de emprendimientos que implican un riesgo económico bajo, por lo que no se justifica la utilización de figuras jurídicas que protejan el patrimonio de los socios, limitando su responsabilidad.

Compartimos lo afirmado por MILLER en cuanto a que la constitución de la sociedad de hecho puede darse en forma expresa o tácita, esto último cuando se comprueba la existencia de todos los elementos ya descriptos que conforman la sociedad ${ }^{20}$.

La realidad confirma lo afirmado por este autor en cuanto a la discusión de la configuración de una sociedad de hecho entre dos personas, determinando que sea relevante la distinción de esta figura de otras que se dirán.

Así lo ha entendido la jurisprudencia en sentencia n62/013 del Juzgado Letrado en lo Civil de $1^{\circ}$ Instancia donde se determinó la existencia de una sociedad de hecho, a partir del valor significativo de uno de los aportes hecho por los socios, que consistía en una patente de invención en la que se basaba el producto que realizaba la sociedad de hecho: En el caso de autos, habiendo aportado el Sr. Uval el método para la extracción del aceite de hígado de pescado, por él patentado; mientras que la empresa Landasur aportó las instalaciones físicas y el pescado propiamente dicho, ya que existe una vinculación con empresas pesqueras que tienen su asiento físico en el mismo lugar (Potensol, por ejemplo), puede considerarse, en razón de los aportes realizados por cada uno al negocio común, que se constituyó entre las partes una sociedad de hecho. Las sumas abonadas a Uval a través de Atlansur constituían el pago de los servicios de dirección técnica y marketing que éste prestaba a la empresa, pero nada tienen que ver con las utilidades o dividendos de la sociedad, en los cuales, desde el inicio, atento a la importancia de su aporte, tiene derecho a participar ${ }^{21}$.

Como expresamos la sociedad de hecho carece de formalidades, en tanto no se instrumenta en documento público ni privado, lo que genera un problema probatorio al tiempo de pretender probar su existencia o ampararse en otro instituto jurídico, con un régimen aplicable distinto.

\section{Prueba de la sociedad de hecho}

Podemos afirmar que la jurisprudencia ha sostenido variados criterios para determinar la existencia de una sociedad de hecho, sobre todo, producto de la demanda de disolución emanada de alguno de sus socios. En este sentido, ha empleado diversos criterios, teniendo presente lo previsto por el art. 41 de la LSC.

Conforme con el artículo citado la existencia de la sociedad de hecho puede probarse por cualquier medio de prueba admitido legalmente. Ello nos enfrenta, siguiendo a Mi$1 l e r^{22}$, a tener presente las limitaciones que pueden existir en materia probatoria, contenidas en el Código Civil, por ejemplo, en lo que refiere a la prueba por testigos.

Entendemos que la prueba de la sociedad de hecho admite todo medio probatorio que sea legalmente admitido, sin admitir restricciones que provengan de otras normas no particulares del derecho societario. Si la ley es clara, entonces, no debe distinguir el intérprete.

20 MILLER, Alejandro, "Actividad Empresarial Mercantil y Sociedad de Hecho" en LJU tomo 149, La Ley, 2014, Revista Online.

21 Sentencia 62/013, JL Civil 19 , 23/9/2013, Tommasino.

22 Miller, op. cit. 
En segundo lugar, procurar hacernos de prueba por escrito de la sociedad de hecho es francamente contradictorio. Debemos partir de la idea de que no existe prueba por escrito de la sociedad de hecho, si la hubiera, estaríamos ante una sociedad irregular. Sí podemos encontrar actuaciones de la sociedad frente a terceros, como la administración tributaria u otros sujetos de derecho privado, de donde podemos deducir su existencia.

Pero antes de analizar casos concretos, debemos tener presente que son aplicables a la prueba de la sociedad de hecho las reglas generales que rigen sobre la carga de la prueba y la contradicción. La jurisprudencia ha hecho pesar sobre las partes en el proceso las consecuencias de no controvertir la existencia de la sociedad de hecho ${ }^{23}$, o la falta de asistencia personal a la audiencia preliminar de un proceso ordinario.

Así, en sentencia $\mathrm{n}^{\circ} 10 / 006$ del TAC $7^{\circ}$, se utilizó la absolución de posiciones, mediante la cual los interrogados admitieron que constituían una sociedad de hecho, cuyo giro era el flete con camiones que se detallaron, que él mismo firmaba las órdenes de compra de combustible y lubricantes, utilizando el nombre de fantasía "TRANSPORTES BB. ${ }^{24 "}$

En otro caso, resuelto por sentencia ${ }^{\circ} 108 / 012$ de JL Civil de $17^{\circ}$, se infirió la existencia de la sociedad de hecho de la distintas actividades comerciales que han emprendido sus socios, utilizando un único número de RUT: Se ha acreditado en autos que, desde el año 2003 a la fecha, tienen una relación comercial con la actora y constituyen a su vez una sociedad de hecho denominada "Julio y Enrique Cabrera" y bajo esa denominación se han presentado en las operaciones comerciales (...) En todo el relacionamiento comercial, primero con CARLI y luego con COPAGRAN, los demandados comparecieron en forma individual con un único número de RUT que se repite en todas las facturas que les emitió la actora, consintiendo ese tratamiento, sin que el hecho de que Julio Cabrera tenga otro número de RUT ante DGI como productor tambero, invalide estas conclusiones porque se trata de dos especialidades bien delimitadas dentro de la producción agropecuaria ${ }^{25}$.

En otro caso se rechazó la existencia de una sociedad de hecho que se habría originado en un noviazgo (no concubinato), en tanto no se logró demostrar por la actora que hubiera comprado o colaborado económicamente en la compra de los bienes que aparecen adquiridos solo por el demandado, siendo de destacar que tampoco se probó que los préstamos de dinero que aquella probó haber contraído mediante los documentos individualizados agregados con la demanda estén causalmente vinculados a tales adquisiciones. Idéntica apreciación merecen los retiros de dinero que probó haber efectuado de su caja de ahorro. Los testigos que declararon en autos sobre el punto son testigos "de oídas", que relataron lo que la actora les contó, por lo que carecen de eficacia convictiva ${ }^{26}$.

También se juzgó como insuficiente la prueba de la existencia de una sociedad de hecho en un proceso de ejecución, cuando se estaba ejecutando inmuebles rurales que figuraban a nombre de sus socios. La jurisprudencia entendió que debía primar la información registral presentada en el expediente, sin importar la prueba de la sociedad de hecho que se pretendió realizar, en tanto no importaba diferencia entre la sociedad de hecho y sus socios ${ }^{27}$.

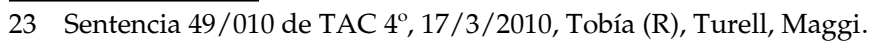

24 Sentencia 10/006 de TAC $7^{\circ}, 1 / 2 / 2006$, Bello (R),Couto y López Ubeda.

25 Sentencia 108/012 de JL Civil $7^{\circ}, 3 / 12 / 2012$, Landeira.

26 Sentencia 194/009 de TAC 6º 5/8/2009, Hounie (R), Martínez Rosso, Klett.

27 Sentencia SEI-0005-000010/2015 de TAC 2 , 18/3/2015, Franca (R), Sosa Aguirre, Pérez Brignani. 


\section{Distinción de la sociedad de hecho de otras figuras en la jurisprudencia}

La falta de formalidades para la constitución de la sociedad de hecho hace que esta figura societaria se puede presentar emparentada con otras formas jurídicas. Es decir, debemos estar advertidos de no estar creando una "apariencia" de sociedad, capaz de confundir a terceros, cuando recurrimos a otras figuras jurídicas que implican cooperación.

a) El condominio

Parece sencillo, a primera vista, decir que el condominio no configura una sociedad en tanto no concurren los elementos antes mencionados para la existencia de la sociedad de hecho.

El Código Civil en su art. 1876 determina que la simple comunidad de bienes o de intereses, aun resultantes de un hecho voluntario de las partes, no constituye una sociedad.

Ahora, entendemos que respecto a estas dos figuras pueden presentarse escenarios de confusión, en donde la sociedad se fundamente en un condominio. Sería el caso de una sociedad de hecho que tenga como asentamiento un bien en el que los socios son condóminos, y el bien haya sido aportado a la sociedad. Lo importante, entonces, es que deben darse todos los elementos para que exista sociedad, sin importar la figura del condominio, que deberemos analizar a la hora de verificar la existencia de aportes.

Es decir, la simple existencia de condominio no configura sociedad, pero tampoco excluye de plano la posibilidad de que exista.

Así lo vimos al mencionar el caso "Buckstein" (Sentencia 172/016 del TAC 2) donde la demandada era condómina junto con sus hermanos de un bien, a pesar de lo cual se determinó que no recaía sobre ella la calidad de socia de la sociedad de hecho.

b) El leasing

La figura del leasing aparece vinculada a la sociedad de hecho. En sentencia $\mathrm{n}^{\circ} 10 / 012$ del Juzgado Letrado en lo Civil de $19^{\circ}$ Turno se analiza, a raíz de un accidente de tránsito, la posibilidad de demandar a la "sociedad de hecho" existente entre el conductor del taxímetro y el usuario del leasing suscripto respecto del mismo vehículo. La defensa esgrimida por el conductor se basó en que, de la información registral aportada, la única titular del leasing era la codemandada, y que por tanto no existía sociedad de hecho entre ambos. Los codemandados eran familiares ${ }^{28}$.

La sentencia no termina analizando el fondo del asunto, mas es útil para que pensemos si es posible que, a partir de la figura del leasing, exista sociedad de hecho. Entendemos que sí, pero para ello deberán demostrarse que existen todos los elementos de la sociedad de hecho, entre ellos el aporte, el que puede consistir en un vehículo (en este caso un taxi) obtenido a partir de un leasing.

Consideramos que la defensa basada en la información registral no es suficiente. Ello por cuanto pudo haberse omitido la comunicación al registro del aporte, o fue una situación que se creó de facto, como sucede habitualmente, y no hubo oportunidad de

28 Sentencia $10 / 012$ de JL Civil $19^{\circ}, 28 / 2 / 2012$, Tommasino. 
efectuar tal comunicación. Debemos recordar que la publicidad registral tiene en principio función de oponibilidad, y excepcionalmente la función constitutiva de situaciones jurídicas (Ley 16.871).

c) La relación laboral

Existe abundante jurisprudencia que se ha enfrentado a la defensa opuesta por el demandado de que la situación, por la que se reclaman rubros salariales adeudados, era una sociedad de hecho.

Es lógico que exista algún tipo de duda acerca de si se trataba de una sociedad de hecho o de una relación laboral, encubierta bajo la forma de sociedad. En la realidad, estas situaciones son de difícil distinción. La relación laboral se caracteriza por la subordinación jurídica entre el empleador y el trabajador, aspecto que no figura entre los elementos de la sociedad de hecho. Pero también es cierto, y no se puede descartar, que en una sociedad de hecho pueda existir alguien que tome las decisiones cruciales desde el punto de vista empresarial, sin que el otro socio se convierta en trabajador subordinado.

¿Qué criterios brinda la jurisprudencia para distinguir ambas instituciones jurídicas?

Un primer criterio que aporta la jurisprudencia radica en que debe demostrarse fehacientemente la existencia de la sociedad de hecho, carga que pesará sobre el demandado. Ante cualquier duda hermenéutica se deberá aplicar el criterio que impone el derecho laboral de resolver en favor del reclamante ${ }^{29}$. Entendemos que tal criterio no es correcto, principalmente porque la figura de la sociedad de hecho no se aplica en subsidio de otras instituciones jurídicas. Incluso, aplicar criterios de interpretación del derecho laboral presupone que se está ante una relación laboral, lo que también habrá de demostrarse.

En otro caso se discutió si choferes que figuraban como socios de hecho eran o no trabajadores, y por tanto tenían derecho a reclamar haberes salariales. El criterio empleado por el tribunal en el caso concreto radicó en que no se repartían beneficios o pérdidas, sino que se pagaba un honorario fijado por una de las partes de la relación. En el mismo caso también se consideró que la exclusividad de la prestación de servicios, la profesionalidad, la amenidad de los frutos del trabajo y el pago de viáticos eran indicios de que se estaba ante una relación laboral ${ }^{30}$.

En sentencia 25/011 del TAT $1^{\circ}$ se afirmó que la sociedad de hecho no puede ser probada mediante afirmaciones de testigos, sino que la carga de la prueba de la existencia de la sociedad de hecho, que tenía trabajadores a cargo, debía surgir de las planillas del Ministerio de Trabajo e inscripción en BPS, carga que no cumplió la parte demandada ${ }^{31}$.

d) Coproducción audiovisual

La jurisprudencia ha tenido oportunidad de pronunciarse respecto a la existencia de sociedad de hecho en materia de coproducción audiovisual. En el caso, el actor es el autor de una obra preexistente al audiovisual, titulado "El F." y que fue incluido en la obra audiovisual "B.B". Alega que entre las partes existió una sociedad de hecho con el objeto

29 Sentencia 102/011 de JL Trabajo 10 , 30/8/2011, Fernández Francesch.

30 Sentencia 86/011 de JL Trabajo 10 , 8/8/2011, Fernández Francesch.

31 Sentencia 25/011 de TAT $1^{\circ}$, 16 de febrero de 2011, Morales Martínez (R), Posada, Rossi. 
de coproducir el audiovisual "B.B". El demandado no revistió la calidad de productor exclusivo, y por lo tanto tenía derecho a los dividendos derivados de tal sociedad.

El TAC $6^{\circ}$ entendió que "en efecto, en su propio escrito de demanda, el actor señala que en marzo de 2003 el demandado se puso en contacto con él con el objeto de llevar adelante la realización de un proyecto audiovisual en conjunto, el cual sería explotado tanto a nivel nacional como internacional. El accionante reconoce que en base a este acuerdo -que se traducía en la coproducción del audiovisual-comenzó a escribir la miniserie, titulándola "El F" y que, cuando terminó de escribir el tercer capítulo, registró el guion en AGADU, el 18 de diciembre de 2003. Los propios dichos del accionante conducen a la conclusión de que "El F" no es una obra preexistente, adaptada para un audiovisual, sino que en realidad se trata de un guion creado específicamente para ser incluido en el audiovisual "B.B" $"$ "32.

Entendemos que el aporte a la sociedad de hecho puede consistir en trabajo, y no necesariamente en alguna cosa material susceptible de valoración pecuniaria. En autos, debió analizarse si efectivamente existió sociedad de hecho entre el actor y productor demandado, aspecto que se ignoró, haciendo primar las normas relativas a derechos de autor.

\section{El objeto de la sociedad de hecho}

\section{a) Definición del objeto social}

Al momento de la constitución los socios definirán cuál será el objeto social de la sociedad de hecho que están creando, y esto lo podrán hacer en forma expresa o tácita.

Entendemos que el objeto social en las sociedades de hecho incide en las relaciones internas entre los socios, a diferencia de lo que ocurre en los demás tipos sociales de la LSC, donde incide en las relaciones entre los socios y frente a terceros.

Por tanto, consideramos que el objeto social de la sociedad de hecho puede verse desde dos ópticas distintas:

En el plano de las relaciones internas, el objeto social es válido y oponible entre socios. Por lo tanto, en caso de que uno de los socios actúe en violación del objeto social acordado, los demás podrán reclamarle los daños y perjuicios derivados de su actuación, sin perjuicio de otras consecuencias que derivan de delimitar el objeto social que se comentarán en la sección dedicada a la "Relación entre Socios".

- En el plano de las relaciones externas de la sociedad, el objeto carece de oponibilidad, y por lo tanto entendemos que carece de relevancia. De esta manera la LSC logra un régimen determinantemente negativo para los socios ya que ninguno de ellos podrá desconocer lo hecho por otro en representación de la sociedad, aun cuando sea en infracción al objeto social previamente acordado.

b) El objeto social desde la óptica de los terceros

CABANELLAS DE LAS CUEVAS afirma que el objeto de la sociedad de hecho es particular porque se determina a través de las actividades que la sociedad de hecho lleva

32 Sentencia 280/007 de TAC 6 ${ }^{\circ}, 23 / 10 / 2007$, Klett (R), Hounie, Martínez. 
a cabo: los acuerdos que existan entre los socios para determinar el objeto carecen de efecto frente a terceros (...). Si los socios acuerdan unánimemente actuar conforme a cierto objeto, el incumplimiento con tal acuerdo hará responsables a quienes lo produzcan, pero ello no hará el objeto contractualmente oponible frente a terceros ${ }^{33}$.

Compartimos con el mencionado autor que el objeto de la sociedad de hecho presenta particularidades, y que bajo nuestro régimen jurídico el mismo es inoponible. Pero vamos más allá, en tanto entendemos que desde la óptica de los terceros las sociedades de hecho tienen un objeto sumamente amplio, por el que pueden realizar cualquier tipo de actividad lícita, que no requiera de un tipo social específico o les esté prohibido.

A nuestro juicio ello implica una extensión de lo afirmado por el autor español en cuanto a que el objeto de la sociedad de hecho se forma a partir de las actividades desarrolladas; por el contrario, tratándose de una sociedad de hecho, de principio, ella puede realizar cualquier tipo de actividad que no esté prohibida para ese tipo social o que requiera un tipo social particular, desde la óptica de los terceros.

Y ello encuentra su fundamento en la inoponibilidad del objeto social frente a terceros. Podremos discutir si, en virtud de las actividades desarrolladas previamente con terceros, podría alegarse mala fe del tercero que contrata con la sociedad de hecho, cambiando notoriamente el giro habitual de sus negocios, pero entendemos que ello no puede fundarse en el objeto social, dado que tal defensa se encuentra literalmente prohibida (art. 39 de la LSC).

No compartimos lo que afirma CABANELLAS en cuanto a que el objeto de la sociedad de hecho esté determinado por su actividad. El autor señala: "supongamos que una sociedad de hecho ha explotado un determinado café. ¿será su objeto único la explotación de ese café, o bien la explotación del local en que opera tal café, o la explotación de cafés en cualesquiera locales, o la explotación de negocios gastronómicos en general, o cualquier otro conjunto de actividades que comprenda a la efectivamente realizada? No hay razón lógica o jurídica para optar inmediatamente por alguna de estas posibilidades. La solución, a nuestro entender, debe basarse en el hecho de que la exteriorización de la actividad de la sociedad de hecho obra como publicidad de ese elemento del contrato de sociedad. (...) Una segunda dificultad se plantea cuando la sociedad desarrolla múltiples actividades a lo largo de su existencia, algunas de las cuales dejan de llevarse a cabo. En tal hipótesis, podría sostenerse que el objeto de la sociedad de hecho está constituido, en cada momento, en función de la actividad que la sociedad realiza en ese momento. Pero ello sería contrario a lo que sucede normalmente en las sociedades regulares, en las que el hecho de que una actividad cese no implica que tal actividad deje de formar parte del objeto".

La prueba de la actividad realizada podrá ser útil en sede de relación entre socios para el caso en que alguno de ellos actúe en infracción del objeto social convenido. También podrá ser útil, según comentaremos, para probar la existencia de mala fe del tercero que actúa con una sociedad de hecho, pero de ningún modo puede suponer una limitación del objeto social y menos una forma de lograr la publicidad, que jurídicamente le esta inhibida.

33 Cabanellas de las Cuevas, G. "Derecho Societario. Parte General. Sociedades nulas, irregulares y de hecho" (1997), Editorial Heliasta SRL, pág. 476 a 478. 
Nada impide que las sociedades regulares incluyan en su objeto actividades que no practicarán, por lo que nada justifica que el objeto de la sociedad comercial de hecho esté restringido por su actividad realizada. Lo afirmado por el autor español lleva a un resultado incongruente por cuanto pone en carga de los terceros conocer qué actividad en concreto realiza la sociedad y qué actividades dejó de realizar, creando una publicidad "de hecho" que empeora su situación, en cuanto nuestra LSC establece un régimen de protección a los terceros y gravoso para los socios de la sociedad de hecho.

Por último, entendemos que nada aporta apreciar con tanta severidad el objeto social cuando bastará un acuerdo unánime tácito para modificar el objeto social, emprendiendo una nueva actividad.

La segunda dificultad señalada por CABANELLAS tampoco es compartida. Entendemos que no basta con dejar de realizar una actividad para entender que la misma dejó de formar parte del objeto social, aunque entendemos que tal conclusión deriva de que a juicio de este autor el objeto social se conforma con la actividad realizada por la sociedad. Tal extremo no ocurre en las sociedades regulares y nada justifica que el régimen de la sociedad de hecho sea diferente.

No podemos aceptar este razonamiento porque sería incongruente aceptar que una determinada actividad forma parte del objeto social de la sociedad de hecho para los terceros por el simple hecho de desarrollarse, cuando puede ocurrir que los socios hayan convenido otra actividad a realizar. Como dijimos, entendemos que desde la perspectiva de los terceros el objeto social es amplísimo.

c) El objeto social desde la perspectiva de los socios

Como comentáramos la determinación del objeto social entre los socios es relevante. Ello por cuanto puede determinar la responsabilidad de cualquiera de ellos por actuaciones en infracción del mismo. Para ello habrá que lograr la prueba de cuál fue el objeto convenido, lo que será verdaderamente complejo en tanto no existe contrato instrumentado por escrito.

Otras consecuencias derivadas de la delimitación del objeto social se comentarán al referir a la "Relación entre socios".

d) La nulidad del objeto social

El objeto de la sociedad de hecho no escapa a las consideraciones generales en la materia, siendo aplicable a él lo previsto en el art. 23 de la LSC: Serán nulas las sociedades cuyo contrato prevea la realización de una actividad ilícita o prohibida, sea con carácter general o en razón de su tipo.

El objeto será ilícito cuando se realiza una actividad contraria a la ley, por lo que es difícil que exista una sociedad comercial regularmente constituida con objeto ilícito, en tanto a la hora de su inscripción registral, la nulidad absoluta del objeto será causal de observación por el Registro (núm. 2 art. 65 Ley 16.871), sin que exista posibilidad de subsanación.

En cambio, el objeto prohibido refiere a una actividad lícita de principio, pero que se restringe a todos los tipos sociales o alguno de ellos en particular ${ }^{34}$.

34 Ejemplo de este tipo de restricción lo encontramos en el art. 518 de la LSC: Las sociedades de responsabilidad limitada no 
Podemos ilustrar esta distinción entre objeto prohibido e ilícito atendiendo a lo resuelto por dos tribunales en un caso cuyo objeto era dilucidar la disolución de una sociedad de hecho.

Se trataba de una sociedad de hecho cuya actividad principal consistía en la actividad de las agencias de loterías y quinielas. El art. 64 de la ley 11.490 establece que los permisos para los agentes de quinielas son personales y solo pueden desarrollarse directamente por los titulares de dichos permisos.

En el caso los actores demandaron la disolución de la sociedad de hecho y su correspondiente participación.

El tribunal de primera instancia entendiós ${ }^{35}$ que existió nulidad absoluta por inidoneidad del objeto de la sociedad, habida cuenta de que no surge probada la existencia del permiso de explotación sin el cual no puede desarrollarse la referida actividad. En cambio, el TAC $6^{\circ}$ calificó el objeto como nulo pues la explotación sólo puede ser hecha por una persona física, y la causa también lo es porque la finalidad de participar en las ganancias y en las pérdidas que resulten del aporte a la sociedad constituye un modo de hacer indirectamente lo que la ley prohíbe hacer directamente, es decir, la explotación por medio de una sociedad ${ }^{36}$.

Entendemos que se trata de un objeto prohibido y no ilícito. La actividad de loterías y quinielas es una actividad lícita, pero regulada en atención a intereses de terceros que están en juego. En particular, se trata de una prohibición general y no especial, en atención al tipo social.

e) Defensa frente a demandas de terceros ¿es posible hacer valer mala fe del tercero por apartamiento notorio del giro de los negocios habituales?

Es cierto que el legislador ha creado un régimen notoriamente gravoso para los socios de la sociedad, y este ha de ser el punto de partida necesario para cualquier interpretación.

Si partimos únicamente del texto de la norma, la conclusión a la que llegaríamos es: no importa la actuación del tercero. Es decir, no importa su buena o mala fe a la hora de contratar con la sociedad.

El artículo 38 de la LSC establece a texto expreso que cualquiera de los socios representará a la sociedad. Asimismo, el artículo 37 de la LSC establece que ni la sociedad ni los socios podrán invocar respecto de cualquier tercero, derechos o defensas fundados en el contrato social.

En un análisis primario de la norma, es evidente que se le busca dar una protección íntegra al tercero. Es decir que, aún actuando de mala fe, su interés será protegido y serán de aplicación las disposiciones relativas a la responsabilidad de los socios y de los administradores en sede de sociedad de hecho.

Al decir que el tercero actúa de mala fe, nos referimos a aquellas situaciones en las que el tercero conoce algún vicio que afecta la relación que él tiene con la sociedad, que se encuentra fundada en el contrato social, o en algún otro documento de carácter societario.

podrán tener por objeto actividades de intermediación financiera o de seguros.

35 Sentencia 66/013 de JL Artigas $2^{\circ}$.

36 Sentencia 198/2014 de TAC 6º,23/10/2014, Martínez Rosso (R), Klett, Hounie. 
La pregunta que debemos hacernos a la hora de analizar el accionar del tercero de mala fe es: ¿la norma busca penalizar a la sociedad de hecho, o busca proteger al tercero por lo dificultoso que puede ser acceder a la información de la sociedad?

La respuesta que demos a esta interrogante determinará como debemos analizar el punto. Si entendemos que la norma únicamente busca penalizar a la sociedad de hecho, nos es indiferente el conocimiento que pueda tener el tercero con relación al vicio que acarrea el negocio jurídico. Por su parte, si entendemos que lo que se busca proteger es la falta de información que pueda tener el tercero, al momento en que este accede a la información, ya no existe una razón de protección.

En el primer caso, nos encontraríamos frente a una situación universal que permeabilizaría todas las relaciones entre un socio actuando en nombre de la sociedad, y cualquier tercero. En el segundo supuesto, correspondería analizar caso a caso.

La norma en sí misma considerada parece partir de la base del primer supuesto, es decir que no importa la buena o mala fe del tercero. Sin perjuicio de ello, esto no es totalmente de recibo.

No se puede admitir una conducta irrestricta por parte del tercero, dado que esto implicaría permitir que obtenga un beneficio ilícito. Es evidente que, en cualquier supuesto, el tercero preferiría contratar con la sociedad, antes que con cualquiera de sus socios. Contratando con la sociedad, su crédito se vuelve más fuerte, dado que no hay un único deudor, sino que los deudores serán la sociedad sumado a todos los socios que existan.

En estos casos, el tercero se aprovecha de una anomalía, por la cual obtiene una ventaja en perjuicio de la sociedad de hecho (y de los demás socios). Este procedimiento anómalo vicia el contrato. ${ }^{37}$ Sin perjuicio de ello, habría que determinar caso a caso si es que existió mala fe de un tercero a la hora de contratar. En el caso de que se verifique la mala fe, y esta sea comprobable, será responsabilidad del Juez evitar que la sociedad sea responsable por las obligaciones asumidas por uno de los socios en contravención de lo acordado con los demás, en conjunto con un tercero de mala fe.

En caso de la existencia de la mala fe, debería ser de aplicación lo previsto en el inciso final del artículo 79 de la LSC, siempre que se encuentre en una de las hipótesis previstas. ${ }^{38}$ En estos dos casos, la sociedad no quedará obligada.

Por tanto, en el caso de que el tercero conociera las limitaciones del objeto social, se pueden dar dos supuestos. En un primer caso, si el supuesto ingresa en los últimos tres incisos del artículo 79, la sociedad no quedaría obligada. En los demás casos, la sociedad quedaría obligada en principio, debiendo recurrir a la actuación de un juez para que dilucide la situación. Sin perjuicio de ello, en ningún caso la sociedad debería ser responsable.

37 Gamarra, Jorge, Buena Fe Contractual, Montevideo, FCU, 2011, p. 152.

38 Inc. Final del art. 79 de la LSC: En los casos de los dos incisos anteriores la sociedad no quedará obligada cuando el tercero tenga conocimiento de la infracción.

Los dos incisos anteriores refieren a: i) cuando las facultades de los administradores se encuentran limitadas por el contrato social; y ii) cuando se trate de obligaciones asumidas por el representante en infracción de la organización plural, en títulos valores, contratos entre ausentes, contratos de adhesión o concluidos mediante formularios. 


\section{Aportes, avaluación y participación social}

Con relación al aporte, es preciso remitirnos al artículo 58 de la LSC. Este establece en su inciso $2^{\circ}$ que los aportes "podrán consistir en obligaciones de dar o hacer". No hay mayores comentarios a realizar con respecto a esto. Sin perjuicio de ello, sería conveniente determinar cómo procederá la valoración de los aportes, dado que no se instrumentará por escrito. Esto será tratado más adelante.

Es imprescindible que los socios puedan probar haber cumplido con sus aportes para probar su participación en la sociedad de hecho. La falta de documentación de la sociedad trae aparejada la complejidad que puede significar en algunos casos la prueba del aporte.

En la sentencia $n^{\circ} 62 / 013$ del Juzgado Letrado en lo Civil del $19^{\circ}$ Turno, se logra demostrar la existencia de una sociedad de hecho probando que el socio había realizado un aporte fundamental, y sus socios habían realizado otros aportes de infraestructura y materia prima.

En el caso mencionado, se termina definiendo la existencia de la sociedad de hecho por la efectiva configuración de los aportes hechos por los socios. El caso no refleja una gran complejidad ya que, de forma notoria, una parte de la sociedad aportó un espacio donde trabajar y la materia prima y la otra parte aportó la propiedad intelectual mediante la cual llevarían a cabo el proceso.

Puede no ser una tarea imposible la prueba de la realización de aportes a la sociedad, pero su posterior avaluación en caso de disputa y disolución puede convertirse en una complejidad.

¿Como logro valuar mi aporte? En los casos en que los aportes pueden ser fácilmente identificados no habría problema en establecer su valuación. La situación cambia cuando los aportes no son fácilmente identificables. La distinta naturaleza de los aportes también significa la complejidad de su avaluación.

Una posibilidad sería considerar a los socios de las sociedades de hecho como iguales. En todos aquellos casos en los que no se logre divisar una verdadera desigualdad entre los aportes de los socios, estos serían considerados como socios por iguales partes.

Al ser las sociedades de hecho, vehículos jurídicos para pequeños emprendimientos y emprendimientos familiares, es de suponerse que los integrantes de estas sociedades se asociaran por partes iguales.

Una forma de probar que efectivamente existía una diferencia entre las participaciones de los socios en la sociedad sería mediante la división de utilidades. Como es de esperarse, la sociedad en algún momento dará utilidades y estas serán repartidas entre los socios. Si se configurara una diferencia entre los dividendos que son repartidos entre los socios de forma indudable se estaría demostrando que no todos los socios participan de la sociedad por iguales porcentajes. El llevar contabilidad suficiente por parte de la sociedad pondría fin a este problema. 
Se suele pactar, previo a la efectiva asociación, el aporte que harán los socios y su porcentaje en la sociedad. Es natural que uno quiera conocer el rol que ocupará en una sociedad antes de unirse y antes de realizar su aporte. La complejidad que puede significar su prueba llevaría a los jueces a reconocerles a los socios idénticas participaciones en la sociedad de hecho, en sus ganancias y en sus pérdidas salvo prueba en contrario.

En caso de que un socio demande dividendos, ya sea, producto de la disolución o durante la vida normal de la sociedad de hecho, se podrá plantear procesalmente en un incidente de liquidación, una vez que ya haya obtenido una sentencia de condena ${ }^{39}$.

\section{Efectos entre socios}

\section{Oponibilidad del contrato entre los socios}

Como una primera aproximación al tema, cabe señalar los antecedentes parlamentarios de la $\mathrm{LSC}^{40}$. Hubo una intención del legislador de ser duro y poco flexible con la sociedad de hecho. Incluso la regulación aprobada -si bien sigue siendo ampliamente desfavorable- es mucho más flexible que la prevista en los antecedentes parlamentarios de la LSC, donde se imponían importantes consecuencias negativas para la sociedad de hecho.

A modo ilustrativo, el artículo 37 del proyecto de ley presentado disponía la inoponibilidad del contrato social entre los socios. De esta forma, el legislador intentó, en un primer momento, desestimular la constitución y operatividad de la sociedad de hecho en forma casi absoluta. De haberse adoptado esta fórmula, el contrato social por el que se constituye la sociedad de hecho no cumpliría con el artículo 1247 del Código Civil ${ }^{41}$. Con la actual fórmula expresada, sí nace un haz obligacional entre las partes contratantes.

El legislador optó por quitar la inoponibilidad del contrato social entre socios, en tanto hizo primar las disposiciones referidas a la buena fe contractual. De lo contrario, habría habilitado a que las partes se contradijeran con respecto a lo establecido en el contrato social. Asimismo, si el contrato no fuera oponible entre socios, no habría sociedad, dado que si bien el contrato es verbal, este debe obligar a las partes contratantes.

Es preciso destacar que aún en la LSC queda algún resabio del trámite parlamentario que hace a la precariedad jurídica de la sociedad de hecho. Esto se ve, y de forma muy clara en el artículo 43 de la LSC ${ }^{42}$. La ley confiere a cualquiera de los socios la posibilidad de notificar a los demás y solicitar la disolución de la sociedad de hecho.

Por tanto, la eficacia del negocio, va a alcanzar a aquellos que dieron origen al negocio jurídico, como parte sustancial. ${ }^{43}$ Más allá de esto, la actual redacción del artículo 37 establece en su inciso primero ${ }^{44}$ una particularidad especial con relación a las demás so-

39 Sentencia 5/006 de TAC 4ㅇ, de 1/02/2006, Turell (R), Larrieux y Tobía Fernández.

40 Informe de la Comisión Especial de la Cámara de Representantes. Carpeta 885/1987. Distribuido 30699/0.

41 Artículo 1247 del Código Civil: Contrato es una convención por la cual una parte se obliga para con la otra o ambas partes se obligan recíprocamente a una prestación cualquiera, esto es, a dar, hacer o no hacer alguna cosa. Cada parte puede ser una o muchas personas.

42 Art. 43 de la LSC: Cualquiera de los socios de una sociedad irregular o de hecho podrá exigir su disolución. Esta se producirá a la fecha en que el socio notifique fehacientemente su decisión a todos los consocios. (...)

43 CAFFARO, Eugenio y CARNELLI, Santiago, Eficacia Contractual, FCU, 1996, Montevideo, p.39.

44 Art. 37 de la LSC: Ni la sociedad ni los socios podrán invocar respecto de cualquier tercero, derechos o defensas fundados en el 
ciedades comerciales. Esta disposición prevé la inoponibilidad del contrato social frente a terceros tanto por parte de la sociedad, así como por parte de los socios, este punto será analizado más adelante.

\section{Deber de lealtad}

El art. 85 de la LSC dispone que los administradores y representantes de las sociedades comerciales no pueden competir con la sociedad en la que ejercen sus funciones, salvo autorización expresa para ello.

En el caso de la sociedad de hecho todos sus socios son administradores y representantes, bajo el régimen legal, y por lo tanto le son aplicables esas restricciones.

De la lectura exegética del art. 85 de la LSC surge que la limitación está restringida a las actividades que realiza la sociedad, término que no es sinónimo de objeto social. Es decir, la restricción comprende únicamente la actividad que efectivamente ejerce la sociedad, y no otras que pueden estar previstas en su objeto social y que no sean desarrolladas.

\section{Actuación de mala fe}

Los administradores y representantes deben actuar de conformidad con las leyes y con la diligencia del buen hombre de negocios (art. 83 de la LSC). Estos deberes hacen pasible de responsabilidad a los administradores y representantes que actúen en infracción de dichos deberes. En el caso de la sociedad de hecho, esta responsabilidad pesa sobre los socios.

A modo ilustrativo podemos mencionar las sentencias n ${ }^{\circ} 291 / 010$ de TAC $4^{\mathrm{o} 45}$ y 10/013 de JL Civil 1946. Se trataba de una acción por daños y perjuicios impetrada por un socio de una sociedad de hecho titular de un arrendamiento donde funcionaba un local de una red de cobranzas, contra la otra socia y terceros. Los hechos consistieron en que la socia, en representación de la sociedad de hecho, rescindió el contrato de arrendamiento donde funcionaba la sociedad, y celebró un nuevo contrato con el mismo objeto, pero en representación de otra sociedad de hecho con otros integrantes. A los pocos días, la socia demandada ejerció el derecho de disolución de la sociedad de hecho previsto en el art. 42 de la LSC. El actor reclama daño emergente y lucro cesante.

Se entendió que hubo actuación de mala fe de la socia, quien ejerció sus derechos en forma abusiva, causando un daño al otro socio, que se vio imposibilitado de mantener sus ingresos de dicho local comercial: "La circunstancia que se trate de una sociedad de hecho en la especie, en nada cambia las conclusiones las que se arriba. Los hechos de los que fuera protagonista Mayra Martínez, en especial los vinculados con el contrato de arrendamiento, referidos en la prueba, aunado al hecho que Martínez quedó luego como empleada dependiente de las restantes co-demandadas prestando funciones en el mismo local, constituyen, un accionar ilícito de Martínez, quien en convivencia con las titulares del Abitat ${ }^{47}$ procedió a excluir de la sociedad que había conformado y del propio local comercial del cual era arrendatario, a Dasque ${ }^{48 "}$.

contrato social.

45 Sentencia 291/010 de TAC $4^{\circ}, 8 / 12 / 2010$, Maggi (R), Tobía, Turell.

46 Sentencia 10/013 de JL Civil 19 ${ }^{\circ}, 11 / 3 / 2013$.

47 Debió decir "Abitab". Este agregado nos pertenece.

48 Sentencia 10/013 de JL Civil 19. 
Entendemos que el caso citado es relevante en tanto hace una distinción respecto a los rubros reclamados: "En lo que se refiere al daño emergente reclamado se observa que, en puridad, refiere a perjuicios provocados a la sociedad de hecho que integraba el accionante, lo que tiene relevancia en cuanto, por una parte, se advierte que no tiene legitimación porque no actúa por la sociedad sino en forma individual y, asimismo, porque dicha pretensión debe plantearse $y$ resolverse en la liquidación de la sociedad de hecho (Artículos 167 y ss. de la Ley No. 16.060) en trámite según surge del acordonado (...). En cambio, no es compartible dicha solución en lo que respecta a la pretensión indemnizatoria del lucro cesante porque se trata de un rubro de carácter personal del accionante y se invoca responsabilidad de MM en el ámbito de la sociedad de hecho y con fundamento en el Artículo 83 LSC. ${ }^{4 \prime \prime}$.

\section{Efectos entre la sociedad y los terceros}

En tanto persona jurídica, la sociedad de hecho puede trabar relaciones jurídicas con terceros.

La representación de la sociedad estará a cargo de cualquiera de los socios (art. 38 LSC). Esta es una solución legal, que a nuestro juicio no admite pacto en contrario. No se trata de una hipótesis de inoponibilidad del contrato social, sino que se trata de un tipo de representación que impone la LSC.

A ello se acompaña un régimen de responsabilidad gravoso. Este régimen se caracteriza por la responsabilidad solidaria de los socios, sin posibilidad de oponer el beneficio de excusión ni cualquier otra limitación que se funde en el contrato social (art. 39 LSC).

Los terceros podrán atacar tanto el patrimonio de la sociedad así como el patrimonio de los socios y administradores, que hayan intervenido en las operaciones. Es decir, que en el caso de los administradores el régimen establece un requisito más, que consiste en la intervención en el acto que genera la responsabilidad (art. 39 LSC).

Aquí vemos una de las grandes desventajas que recae sobre la sociedad de hecho, y que en definitiva hace que este régimen sea desalentador para quienes decidan emprender bajo este tipo social, aunque por desconocimiento lo hacen igual.

Así, en sentencia $\mathrm{n}^{\circ} 2 / 2020$ del TAC $7^{\circ}$, se dispuso la extensión de la responsabilidad frente al tercero afectado al otro socio, que no fue partícipe personal del incumplimiento del contrato: A pesar de que el otro integrante de la sociedad de hecho, Sr. Romero, no tuvo participación alguna en el episodio, la actuación flagrantemente violatoria de los deberes asumidos en el contrato de concesión, perpetrada por uno de los socios, se extiende al restante, configurando ambas personas físicas una unidad inescindible en tanto componen la referida figura societaria ${ }^{50}$.

Ahora, la debilidad del sistema de representación impuesto hace que pueda resultar difícil determinar si la actuación de quien es socio de una sociedad de hecho se hace a título personal o en nombre y representación de la sociedad.

El TAC $3^{\circ}$ en sentencia 60/018 discutió si la actuación en un contrato de mutuo de quien era socia de una sociedad de hecho fue a título personal o en nombre y representación de la misma. Esto era clave en tanto esto legitimaba pasivamente a los restantes

49 Sentencia $291 / 010$.

50 Sentencia $2 / 020$ de TAC $7^{\circ}, 3 / 2 / 2020$, Tommasino (R), Cabrera, Ettlin. 
socios de la sociedad de hecho. En el caso se logró demostrar que con el préstamo se pagaron deudas de la sociedad de hecho, por ende, concluye el sentenciante que la socia requirió el préstamo por la sociedad, debiendo por ende, responder los socios ${ }^{51}$.

Es decir, podemos afirmar que la jurisprudencia determinó la existencia de un criterio económico que permita definir si existe o no actuación en nombre y representación de la sociedad de hecho.

Comentario aparte merece el art. 40 de la LSC, que regula las relaciones entre los acreedores sociales y de los particulares de los socios. Conforme este artículo, las relaciones entre ambos tipos de acreedores, incluso en caso de concurso, se juzgarán como si se tratara de una sociedad regular.

Ahora, entendemos que este artículo tiene una dificultad práctica en relación con la sociedad de hecho. ¿A qué sociedad regular asimilamos la sociedad de hecho? Tratándose de una sociedad de hecho es evidente que los socios no eligieron, probablemente por desconocimiento, un tipo social de los específicamente regulados. Una solución sería asimilarlo al régimen de la sociedad colectiva, que es sumamente amplio.

De todos modos, consideramos que este artículo era innecesario. En particular, desde que se reconoce la personería jurídica de la sociedad de hecho, es consecuente que no podrá responder el patrimonio social por las deudas de los socios. No obstante, en tanto existe solución legal en ese sentido, el patrimonio de los socios responde por las deudas sociales.

Será cuestión de cada caso concreto determinar sí el bien en cuestión pertenece al socio o a la sociedad de hecho. Entendemos que, en caso de existir información registral disponible en cuestión al bien (ej.: inmuebles, vehículos automotores), debe estarse a la titularidad que surja de la información registral.

\section{Cesión de derechos de participación sobre la sociedad de hecho}

A nivel del derecho comparado se discute si es posible transferir las participaciones de la sociedad de hecho, en particular, dado el régimen de responsabilidad que pesaría sobre el cedente de la cuota.

Una posición sustentada por ROMERO indica que es posible transferir los derecho de participación, pero hasta tanto no exista disolución y se haya hecho pública esta circunstancia (registro mediante), el socio cedente de su participación queda vinculado plenamente en relación a terceros ${ }^{52}$.

En una variante a esta posición, RADRESA sostiene que la responsabilidad del socio cedente se mantiene hasta tanto exista prescripción de las deudas sociales o hasta que se inscriba la disolución de la sociedad.

NISSEN considera inadmisible la transferencia de cesión de partes de interés de las sociedades de hecho, en tanto son modificaciones del contrato social que carecen de absoluta oponibilidad ${ }^{53}$.

51 Sentencia 60/018 de TAC $3^{\circ}, 11 / 4 / 2018$, Kelland (R), Alonso, Opertti.

52 Cabanellas de las Cuevas, op. cit., pág. 529-531.

53 Ídem. 
Compartimos la posición de los primeros autores mencionados en tanto es posible modificar el contrato social, alterando la integración de la misma, aunque calificamos que dicha alteración sería inoponible a terceros, que no tienen forma de conocer - al menos formalmente - que el socio cedente de su cuota ya no integra la sociedad de hecho. La cesión de "cuota" ha sido admitida por la jurisprudencia en sentencia n 322/009 del TAC $6^{\mathrm{o} 54}$.

La responsabilidad del socio cedente cesará con la inscripción de la disolución de la sociedad (art. 43 de la LSC) así como con la inscripción de la regularización (art. 42 de la LSC) bajo un tipo social determinado.

Entonces, en principio, el socio saliente sigue vinculado con la sociedad de hecho, no solo por sus deudas pasadas, sino también por las deudas futuras de estas. La solución legal es coherente. No debemos perder de vista que la responsabilidad de la sociedad se extiende en forma solidaria y sin beneficio de excusión u otro límite fundado en el contrato social a los socios. Entonces, es lógico que se proteja al acreedor que contrató con la sociedad de hecho teniendo presente el patrimonio de los socios de la sociedad.

Pero tal protección entonces debe limitarse. Solo debe protegerse a quienes contrataban con la sociedad antes de producida la cesión de los derechos de participación de la sociedad de hecho. No debe ampararse a quienes empezaron, por primera vez, a contratar con la sociedad de hecho ya producida la cesión de los derechos de participación.

¿Cómo se puede comunicar el egreso de un socio? Creemos que es posible, siguiendo la lógica del comercio, comunicar a las empresas con las que se trabaja en forma corriente el egreso del socio, así como hacer publicaciones en el diario oficial u otros diarios de circulación, de manera de hacer cesar tal confianza de los terceros.

\section{Insolvencia de la sociedad}

Cómo todo sujeto de derecho, una sociedad de hecho puede caer en estado de insolvencia. Como regla general, ante la insolvencia de la sociedad los socios responderán ilimitadamente con su propio patrimonio, más allá de su aporte inicial.

Sin perjuicio de ello, entendemos relevante preguntarnos ¿qué pasaría si la insolvencia de la sociedad surge de un accionar doloso o de mala fe de un socio?

Hay que partir del artículo 83 de la LSC. ${ }^{5}$ Este dispone que los administradores y representantes de la sociedad deben actuar con lealtad, y con la diligencia de un buen hombre de negocios. Asimismo, en caso de no cumplir con este mandato legal, responderán solidariamente frente a la sociedad y los demás socios por los daños derivados de su actuación.

Con relación a los terceros, esta situación no tiene mayores complejidades. No sería coherente exigirle al tercero que pueda accionar únicamente contra el socio que actuó sin la debida diligencia o en forma contraria a la lealtad. Si la sociedad devino insolvente, no

54 Sentencia 322/009 de TAC 6º 25/11/2009, Hounie (R), Klett, Martínez.

55 Artículo 83 de la LSC: (Diligencia y responsabilidad de los administradores y representantes).Los administradores y los representantes de la sociedad deberán obrar con lealtad y con la diligencia de un buen hombre de negocios. Los que falten a sus obligaciones serán solidariamente responsables frente a la sociedad y los socios, por los daños y perjuicios que resulten de su acción u omisión.

El Juez determinará la parte contributiva de cada responsable en la reparación del daño. 
importa si hubo una mala gestión, una actitud dolosa de un socio o, simplemente temas de naturaleza comercial. Los derechos de los terceros no pueden verse afectados por las relaciones internas entre los socios. Por tanto, a la hora de analizar esto desde la perspectiva de los terceros, no es de interés el mencionado artículo 83, sino que lo que importa es el artículo 39 de la LSC. Los socios serán solidariamente responsables.

El artículo 83 recién viene a tomar protagonismo cuando se analiza la relación entre los socios por la actuación contraria a la socio. Esto por razón de que el socio que representó a la sociedad será responsable ante ella y ante los demás socios por el daño causado. Con relación a que implica actuar con lealtad, y con la diligencia de un buen hombre de negocios, no corresponde realizar comentarios que diferencien a la sociedad de hecho de las demás sociedades. Son de aplicación los artículo 84 y siguientes de la LSC.

Por tanto, si bien los socios (y la sociedad) no podrán interponer el beneficio de excusión a la hora de defenderse de un tercero, sí podrán repetir lo pagado ante el socio que representó a la sociedad, en infracción a sus deberes.

Negarle al tercero la posibilidad de reclamarle a cualquiera de las partes mencionadas en el artículo 39 sería un perjuicio injustificado para él. El único supuesto en que no podría reclamarle a la sociedad, y únicamente podría reclamarle al socio que representó a la sociedad, sería si estuviera de mala fe. En los demás casos se le habilita poder accionar contra cualquiera de las partes.

\section{Disolución}

Son aplicables a la sociedad de hecho las normas generales sobre disolución de la sociedades comerciales previstas en los artículos 159 y siguientes de la LSC.

No obstante, el régimen de la LSC prevé la disolución eventual de la sociedad de hecho, a solicitud de cualquiera de los socios, lo que requiere notificación fehaciente a los restantes socios (art. 43 inc. 1 de la LSC).

Si bien la disolución se tiene por hecha en "la fecha en que el socio notifique fehacientemente su decisión a todos los consocios", el inciso segundo habilita a la mayoría de los socios a dejar sin efecto la disolución dentro del plazo de diez días hábiles (según artículo 514 de la LSC), procediendo a regularizar la sociedad.

Vencido el plazo de diez días hábiles, contados desde la notificación fehaciente, la disolución se vuelve irrevocable, privando la ley de cualquier posibilidad de acuerdo entre socios.

La notificación fehaciente, entendemos, se puede cumplir acudiendo a Escribano Público, por notificación judicial o telegrama colacionado con acuse de recibo ${ }^{56}$. Entendemos que, la exigencia de que sea fehaciente priva de cualquier comunicación mediante publicaciones en el Diario Oficial o través de actos implícitos.

Respecto a los terceros, la LSC mantiene el régimen gravoso a la hora de la disolución. La LSC mandata la inscripción en el Registro de Personas Jurídicas, Sección Comercio,

56 Sentencia 10/013 de JL Civil $19^{\circ}$. 
de la disolución de la sociedad de hecho. Hasta ese entonces, no se podrá oponer la disolución, y por lo tanto cualquier socio podrá seguir representando a la sociedad para obligarla. En caso de que alguno de los socios actúe de mala fe, obligando a la sociedad, ya comunicada la intención de disolver la sociedad por otro socio, son aplicables los mismos comentarios respecto a la actuación de mala fe ya mencionados ut supra.

En caso de que los socios disuelven de común acuerdo la sociedad de hecho, es conveniente expresar que se tienen por extinguidos todo tipo de responsabilidad por la actividad social para los socios, sin que existan reclamaciones recíprocas ni pretensiones insatisfechas emergentes de la relación societaria. El TAC $6^{\circ}$ en sentencia $\mathrm{n}^{\mathrm{o}} 80 / 019^{57}$ entendió que esta cláusula es válida y que pone fin a cualquier tipo de reclamación entre socios. Entienden que existió remisión al establecerse en la cláusula segunda: "entendiéndose que en el día de hoy se extingue definitivamente la sociedad relacionada en el numeral Primero literal " $a$ ", sin responsabilidad por la actividad social para ninguno de los socios y sin que existan reclamaciones reciprocas ni pretensiones insatisfechas emergentes -exclusivamente- de la relación societaria..$^{\prime \prime \prime}$

A juicio del Tribunal, dicha cláusula es clara en cuanto se refiere exclusivamente a la relación societaria; por lo que no alcanza a la transacción realizada entre las partes ni afecta a la cláusula penal en ella pactada.

\section{Rescisión por fallecimiento de uno de los socios}

La Sección V del Capítulo I de la LSC no ofrece solución al respecto. Por tanto correspondería, en principio, recurrir a las disposiciones generales de la LSC, siendo de aplicación el artículo $144^{59}$. De esta forma, en caso de que se dé la muerte, incapacidad o inhabilitación de uno de los socios de la sociedad de hecho, la sociedad continuaría con su existencia, debiendo los socios que permanezcan liquidar la parte que le corresponde al socio fallecido, incapacitado o inhabilitado.

El gran problema que se presenta en la sociedad de hecho con respecto a esto, es el caso de la responsabilidad, y como afectaría a los sucesores del socio fallecido. Los socios de la sociedad de hecho responden en forma solidaria con la sociedad y sin poder invocar el beneficio de excusión. Se aparta del régimen de sociedades personales, donde la responsabilidad del socio es subsidiaria en primer lugar, y en segundo lugar, solidaria con la sociedad ${ }^{60}$.

Surge la duda de si esta responsabilidad sería imponible a los sucesores del socio fallecido. Como primera aproximación hay que remitirnos a lo que dispone la ley en su artículo 39 de la LSC en su inciso primero. ${ }^{61}$ La ley es clara al señalar únicamente a los

57 Sentencia 80/019 de TAC 6 $15 / 5 / 2019$, Gómez Haedo (R), Alves de Simas, Bortoli.

58 Sentencia $80 / 019$ de TAC $6^{\circ}$.

59 Artículo 144 de la LSC: El contrato de sociedad se rescindirá parcialmente por la muerte, incapacidad o inhabilitación del socio, salvo disposición legal o pacto en contrario. También será causa de rescisión la exclusión del socio y el ejercicio del derecho de receso en los casos y condiciones previstas por la ley.

60 Artículo 199 de la LSC: (Caracterización). En las sociedades colectivas los socios responderán subsidiaria, solidaria e ilimitadamente por las obligaciones sociales.

61 Artículo 39 de la LSC: Sin perjuicio de la responsabilidad de la sociedad, los socios serán responsables solidariamente por las obligaciones sociales sin poder invocar el beneficio de excusión (artículo 76) ni las limitaciones que se funden en el contrato social. 
socios, sin mencionar a los sucesores de los socios fallecidos. Por tanto, una respuesta aplicando un análisis exegético del artículo sería que esta responsabilidad (solidaria y subsidiaria) no se aplica para los sucesores del fallecido.

Esta solución puede dejar al acreedor social en un estado de desprotección, al menos aparente. Por las características de la sociedad de hecho, se podría dar el caso de que un acreedor contrate con la sociedad debido a la solvencia patrimonial de sus socios.

Entendemos que en caso de que el socio fallezca, la responsabilidad se extenderá a sus sucesores, no en aplicación de la LSC sino en aplicación de las normas relativa a las sucesiones previstas por el Código Civil.

En sentencia $n^{\circ} 67 / 2008$ del Juzgado Letrado de $1^{\circ}$ Instancia de Artigas de $2^{\circ}$ Turno $^{62}$ se desestimó la demanda de disolución y liquidación de la sociedad de hecho impetrada por un socio de esta contra la esposa de quien fuera su otro socio, prefallecido. En autos se alega que, al fallecimiento del socio, la carpintería que ambos tenían permaneció en manos de la cónyuge, quien le prohibió el acceso al local comercial. La demandada alega que no tiene legitimación pasiva, en tanto la sucesora del socio prefallecido es su hija, de conformidad con lo establecido por el Código Civil, y que no existe tal sociedad de hecho, en tanto la misma ya se había disuelto al producirse el fallecimiento.

La justicia admitió la legitimación pasiva de la hija del socio, su sucesora, y que la sociedad de hecho ya se había disuelto al momento del fallecimiento en tanto el actor se había retirado del negocio, abriendo una nueva carpintería, lo que resulta contrastados con testigos: "Sin embargo, de la deposición testimonial, se infiere que la nueva instalación de Franco implicó que dejó de asistir a la anterior y si se vio impedido de ingresar al local como afirma en el presente, pues pudo ocurrir al proceso pertinente en forma inmediata, lo que no hizo. En consecuencia, resulta del cúmulo probatorio allegada a la causa, valorada conforme a derecho que la sociedad efectivamente se había disuelto antes del fallecimiento de Ferreira por decisión de Franco"63.

\section{Conclusión}

A modo de conclusión entendemos que el régimen jurídico aplicable a la sociedad de hecho es notoriamente adverso para quienes, por ignorancia, accidente o voluntad, emprenden mediante este tipo social.

Las ventajas que reporta son escasas en comparación con las cargas que pesarán sobre los socios y administradores de este tipo de sociedades. Es patente que en actividades de menor y mediana envergadura este tipo social resulta acorde dado que el potencial de crecimiento y relacionamiento con terceros no hacen que la sociedad pueda contraer muchas deudas por lo cual los socios no se verían severamente afectados por las consecuencias de la LSC.

En caso de que la actividad de la sociedad de hecho crezca, principalmente en su relacionamiento con terceros, lo aconsejable es regularizar la sociedad de hecho, adoptando un tipo social que satisfaga los intereses de sus socios y los proteja de los riesgos, y en simultáneo, garantice a los terceros la existencia de un patrimonio social claro e independiente.

62 Sentencia 67/008 de JL Artigas $2^{\circ}, 14 / 08 / 2008$, Vega.

63 Sentencia 67/008 de JL Artigas $2^{\circ}$ : 


\section{BIBLIOGRAFÍA}

BIASCO, Emilio (1983), Sociedades de hecho y regulares, Revista AEU, No69.

CABANELLAS DE LAS CUEVAS, G. (1997) Derecho Societario. Parte General. Sociedades nulas, irregulares y de hecho, Editorial Heliasta SRL, Madrid.

CAFFARO, Eugenio y CARNELLI, Santiago (1996), Eficacia Contractual, FCU, Montevideo.

GAMARRA, Jorge (2011), Buena Fe Contractual, FCU, Montevideo.

Informe de la Comisión Especial de la Cámara de Representantes. Carpeta 885/1987. Distribuido 30699/0. Recuperado de: https: / /legislativo.parlamento.gub. uy/temporales/S1988100106997479501.PDF

LAPIQUE, Luis (2020), Sociedades por acciones simplificadas, $1^{\text {a }}$ edición, FCU, Montevideo.

MEZZERA, Rodolfo (1983), Curso de Derecho Comercial, Tomo II, ACALI.

MILLER, Alejandro (2014), Actividad Empresarial Mercantil y Sociedad de Hecho, LJU, Tomo 149.

PIANTONI, Mario (1981), Sociedades de Hecho e Irregularmente Constituidas Civiles y Comerciales, Editora Córdoba. 